\title{
Ergonomia e usabilidade aplicadas no desenvolvimento de website inclusivo em uma
} escola pública de Florianópolis-SC

\author{
Josiane Eugênio \\ profjosianeeugenio@gmail.com \\ Colégio de Aplicação - Universidade Federal de Santa Catarina - CA/UFSC \\ Leonardo Nunes de Brito \\ leonardonunesbrito@gmail.com \\ Universidade Federal de Santa Catarina - UFSC \\ Lizandra Garcia Lupi Vergara \\ lizandravergara@gmail.com \\ Universidade Federal de Santa Catarina - UFSC \\ Maick Horst \\ maick_horst@hotmail.com \\ Universidade Federal de Santa Catarina - UFSC
}

Resumo: O artigo apresenta o desenvolvimento de um website inclusivo, a partir de critérios ergonômicos e de usabilidade, para estudantes com deficiência de uma escola pública de Florianópolis-SC. A intenção é que o website inclusivo desempenhe seu papel enquanto recurso de Tecnologia Assistiva (TA) e se transforme num ambiente pedagógico como estímulo de auxílio ao processo de ensino-aprendizagem. Foram realizados acompanhamentos com dois estudantes com deficiência, sendo que um deles utiliza ferramentas no computador através do Tobii Dynavox Communicator. A partir das observações, de reuniões com as professoras e baseando-se em critérios e princípios ergonômicos, de usabilidade e interface, foi possível extrair um conjunto de necessidades dos usuários. Essas necessidades foram utilizadas para a construção da matriz da qualidade, que resultou nos requisitos técnicos do website para o desenvolvimento de soluções para os requisitos do projeto final. O resultado foi satisfatório e de desempenho rápido, não exigindo uma internet de alta velocidade. Limitações tecnológicas e de tempo impediram o desenvolvimento de alguns recursos necessários, como o teclado virtual inteligente e o banco de dados, que serão implementados no futuro. Concluiu-se com esse estudo que o desenvolvimento e utilização de novas tecnologias em ambientes escolares é de suma importância para se ter uma sociedade mais inclusiva e igualitária.

Palavras-chave: Website inclusivo, Ergonomia, Usabilidade, Educação Especial. 


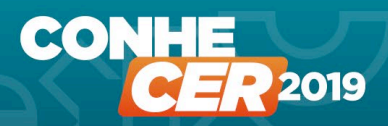

\section{Introdução}

As questões de acessibilidade e inclusão têm sido cada vez mais abordadas e diversas iniciativas e metodologias de aprendizagem já têm sido desenvolvidas em prol de uma igualdade maior entre as pessoas. Entretanto, ainda há muitas barreiras para que a acessibilidade seja efetiva. A inclusão de estudantes público-alvo da Educação Especial, que de acordo com a Política de Educação Especial na Perspectiva da Educação Inclusiva, trata "de pessoas com deficiência, transtorno do espectro autista (TEA) e altas habilidades/superdotação" (AH/SD) no ensino regular exige das instituições de ensino de maneira geral: recursos humanos e materiais; investimentos em estrutura física; confecção, adaptação e gestão de materiais e recursos, que atenda as necessidades específicas de/para cada estudante. (BRASIL, 2008. p.11)

Sabe-se que a criança, hoje cresce rodeada por sistemas tecnológicos, tal realidade facilita a familiarização desta com inúmeros processos e sistemas de comunicação, elas comunicam-se, aprendem e divertem-se com multimídias sejam elas disponibilizadas por meio da internet, em dispositivos portáteis ou móveis, isto torna possível a utilização de tais recursos como ferramentas de apoio em escolas, em geral sem grandes constrangimentos. (GARCEZ et al., 2012)

A familiaridade com a ferramenta (computadores, mídias e jogos) permite o acesso de forma mais dinâmica, diferenciada e em alguns casos personalizada, oferecendo possibilidades para ações de acordo com a preferência e as habilidades dos usuários. Assim, os estudantes público-alvo da Educação Especial (EE) recebem o Atendimento Educacional Especializado (AEE) que é um serviço oferecido pela Educação Especial, que tem como objetivo suplementar e/ou complementar a formação. Durante os AEEs são definidas as estratégias e recursos a serem utilizados, como por exemplo o uso de algum recurso de Tecnologia Assistiva (TA). No caso dos estudantes com deficiência, num sentido vasto, percebemos que a evolução tecnológica caminha na direção de facilitar, nem que seja um pouco, a vida, já que as possibilidades do uso dessas ferramentas, pode proporcionar maior independência, qualidade de vida e inclusão.

Segundo o Censo Escolar feito no país no ano de 2010, cerca de 380.112 alunos com deficiência estavam matriculados em classes regulares do ensino fundamental. Isso demonstra um significativo aumento do número de alunos com deficiência presentes em salas de aula (BRASIL, 2011). Browning (2002) afirma que a deficiência mais comumente encontrada entre esses alunos é a paralisia cerebral.

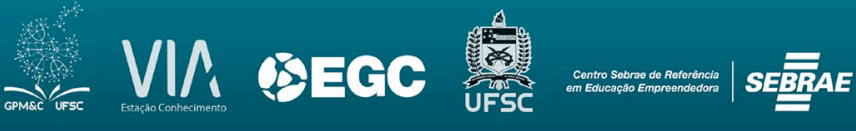


De acordo com o Sistema de Classificação da Função Motora Grossa (GMFCS), a paralisia cerebral pode ser classificada em 5 níveis diferentes, baseando-se no movimento voluntário da criança, especialmente o sentar e o andar. A classificação também depende da idade, e as diferenças entre os níveis têm como base as limitações funcionais, a necessidade de TA, e num grau de importância menor, a qualidade do movimento. (PALISANO et al., 1997). Embora crianças com nível motor que possuam maiores limitações funcionais segundo o GMFCS, principalmente em comparação com outras crianças, e dependência de outros para atividades diárias, a utilização de recursos de Tecnologia Assistiva tem capacidade de oferecer grandes benefícios a esses alunos, especialmente no que diz respeito à necessidade de cuidados e auxílios especiais. (ALVES E MATSUKURA, 2011)

Ao buscar a minimização das limitações sensoriais, funcionais e motoras dos sujeitos com deficiência e potencialização de suas habilidades, pensa-se que as diferentes tecnologias aplicadas para a melhoria das condições de acesso do mesmo, pode ser utilizadas na abordagem didática-pedagógica, como facilitadoras para a funcionalidade e eliminação de barreiras no ensino e na aprendizagem de estudantes público-alvo da EE, proporcionando assim a igualdade de direito ao ensino para todos os estudantes. (GONZAGA, 2012)

Assim, o presente trabalho propõe o desenvolvimento de um website inclusivo, a partir de critérios ergonômicos e de usabilidade, para estudantes com deficiência em uma escola pública, localizada na cidade de Florianópolis-SC, Brasil. Trata-se de uma escola de ensino fundamental, que conta com uma equipe multidisciplinar de professores de Educação Especial, Terapeuta Ocupacional, Fonoaudióloga, Psicóloga, Assistente Social, Enfermeira e Pedagogas, que atuam em conjunto no atendimento á 40 estudantes público-alvo da EE. A escola vêm se adequando às normas de acessibilidade física, possui elevador e rampas de acesso, banheiros adaptados, duas salas para o Atendimento Educacional Especializado (AEE) e conta com alguns produtos/recursos de TA de alta e baixa tecnologia.

\section{O Uso da Tecnologia Assistiva no Ambiente Escolar}

Rocha e Deliberato (2012) esclarecem, com base na literatura internacional, e enfatizam a Tecnologia Assistiva (TA) como a utilização de recursos para diminuir as dificuldades funcionais enfrentadas pelas pessoas com deficiência física e, assim, contribuir para sua independência e qualidade de vida. No Brasil, o conceito adotado de Tecnologia Assistiva, aprovado pelo Comitê de Ajudas Técnicas (CAT) em ata da VII reunião de dezembro de 2007, é o seguinte: 
Tecnologia Assistiva é uma área do conhecimento, de característica interdisciplinar, que engloba produtos, recursos, metodologias, estratégias, práticas e serviços que objetivam promover a funcionalidade,relacionada à atividade e participação, de pessoas com deficiência, incapacidades ou mobilidade reduzida, visando sua autonomia, independência, qualidade de vida e inclusão social. (CAT, 2007)

Para Manzini e Santos (2002 apud ROCHA; DELIBERATO, 2012, p. 73), para implementar algum recurso de TA no ambiente escolar, deve-se, primeiramente, entender a situação e o contexto social no qual o estudante está inserido. Segundo os autores, além de reconhecer as necessidades também do professor, “é necessário escutar seus desejos, identificar as características físicas, psicomotoras e comunicativas, observar a dinâmica do estudante no ambiente escolar", a fim de aumentar a participação deste como autor no seu próprio processo de ensino e aprendizagem.

Nesse contexto, compreende-se que a educação inclusiva amplia-se por meio das organizações dos espaços, tempos e meios para as diferentes formas de aprendizagens, pois promove a organização de serviços, identifica os recursos mais apropriados ao atendimento das necessidades funcionais de cada estudante.

\section{Inclusão Digital por Meio de Tecnologias de Informação e Comunicação (TIC)}

O aumento no uso de Tecnologias da Informação e Comunicação (TIC) e os avanços em softwares e hardwares adaptados permitiu que pessoas com deficiência realizassem tarefas até então consideradas impossíveis (FICHTEN et al., 2009). A inclusão de pessoas com deficiência está diretamente ligada aos avanços vistos nos últimos anos de tecnologias de informação e comunicação e também o acesso destas à Tecnologia Assistiva (TA). Galvão Filho (2009) esclarece que o aumento no uso de TIC tem proporcionado diferentes meios de relacionamento com o conhecimento, assim como abrem portas para novas possibilidades pedagógicas.

Segundo Galvão Filho (2009), é possível classificar as TIC como TA de quatro formas: como sistemas auxiliares; para controle do ambiente; como ferramenta de aprendizagem; e como meio de inserção no mundo do trabalho profissional. Além disso, Galvão Filho e Damasceno (2002) classificam os recursos quanto à utilização de TIC por meio das TA, que são: adaptações físicas; adaptações de hardware e softwares especiais de acessibilidade.

\section{Desenvolvimento de Produto}

Desenvolver produtos de acordo com as necessidades de seus usuários finais é de grande importância, para Soares e Martins (2000). Portanto, a fase mais crítica de um projeto de

\section{- VIA GEGC}


desenvolvimento de produto é o estabelecimento da relação entre as necessidades dos clientes e os requisitos do produto. (DUTRA E GOUVINHAS, 2010)

No que se refere ao desenvolvimento de websites, Santambrogio, Tziviskou e Moli (2006) destacam a importância da acessibilidade e usabilidade a fim de incluir pessoas com deficiência na comunidade web. Enquanto a acessibilidade é garantida através de um conjunto de normas definidas pela World Wide Web Consortium (W3C), chamadas de Web Content Accessibility Guidelines (WCAG), através da Web Accessibility Web (WAI), os autores afirmam que as mesmas não garantem a usabilidade de uma página web. Para Santambrogio, Tziviskou e Moli (2006), é necessário aplicar as normas da W3C adaptando-as a cada conceito específico.

Santambrogio, Tziviskou e Moli (2006) propõem então um modelo para criação de websites, a fim de atender os critérios de acessibilidade e usabilidade. Este modelo tem como principal característica ser centrado no usuário, o que significa que identificar as características e necessidades do público-alvo final é essencial para o desenvolvimento de um website acessível.

De acordo com Mallin e Carvalho (2015), existe uma urgência em incluir o usuário final do produto em todas as etapas do processo de criação, também chamado de Design Centrado no Usuário (UCD - User Centered Design). Com isso, o usuário deve dar feedback sobre o produto durante todo o processo de criação, e não somente ao final. O usuário deve ser ouvido dentro de seu contexto de uso e cultural, além das tarefas que o mesmo pretende desempenhar, a fim de garantir um produto de Tecnologia Assistiva realmente inovador e útil. Isso significa que as emoções do usuário estão no centro de todo o processo. Mallin e Carvalho (2015) afirmam também que a funcionalidade, os desejos e as necessidades possuem uma relação direta com a experiência de uso de um produto.

\section{Metodologia proposta}

\section{Identificação do Problema}

Foi observada no colégio uma falta de recursos de TA. Além disso, foi verificado que alguns dos recursos tecnológicos atualmente disponíveis estão sendo subaproveitados, alguns sequer são utilizados, por falta de conhecimento e treinamento dos profissionais.

\section{Coleta de Dados}

O método utilizado para coleta de dados, e extração das necessidades e requisitos dos usuários (alunos e professores), deu prioridade a uma análise qualitativa, devido a pequena quantidade de estudantes que foi possível acompanhar. Através de observações, algumas

\section{-2) VIN QEeGC}


sessões de contra turno desses alunos foram acompanhadas para análise dos mesmos ao utilizar o computador e outros recursos presentes na sala de AEE. Além disso, foram realizadas entrevistas com professores durante os acompanhamentos de dois estudantes, ambos com diagnóstico de paralisia cerebral, participantes no estudo:

Participante 1 (15 anos): Possui algumas dificuldades motoras, mas consegue andar e movimentar os braços. Não fala palavras por completo, apenas com a ajuda da professora. Utiliza placas de comunicação alternativa para se comunicar. Não utiliza muito o computador, por demonstrar pouco interesse nas atividades disponíveis.

Participante 2 (10 anos): Possui grave dificuldade motora. Não comunica verbalmente, não anda e tem pouco controle sobre os movimentos dos membros superiores e inferiores. De todos os participantes, é o mais familiarizado com o uso do computador e o mais interessado ao usar o Tobii (rastreamento ocular).

Os principais recursos de TA usados com esses alunos são as (i) placas de comunicação alternativa personalizadas, o (ii) Tobii, aparelho que rastreia o movimento dos olhos, e permite que ela utilize funções e softwares no computador, e o (iii) Communicator, software incluído no Tobii, com atividades, jogos e outras funções. Outros recursos são (iv) o Switch Mouse e o (v) rastreamento de um ponto adesivo colado no rosto do aluno.

\section{Definições dos Requisitos de Projeto (Matriz de Qualidade - QFD)}

Para a definição dos requisitos de projeto que devem ser priorizados no desenvolvimento do site para alunos com deficiência da escola pública de ensino fundamental e médio analisada, foi utilizada a Matriz da Qualidade (QFD), que, conforme Sonda, Ribeiro e Echeveste (2000), é uma ferramenta que incorpora a qualidade e necessidades do cliente desde as fases iniciais do desenvolvimento e durante todo seu ciclo de vida. Para King (1987 apud Sonda, Ribeiro e Echeveste, 2000), o QFD é uma ferramenta multifuncional que prioriza as necessidades do cliente, traduzindo isso em soluções inovadoras e efetivas de qualidade.

\section{Desenvolvimento do Website Inclusivo}

Os equipamentos necessários para o uso da plataforma consistem em um computador ou notebook com acesso à internet. $\mathrm{O}$ website foi desenvolvido considerando usuários que fazem uso do Tobii, um dispositivo de rastreamento ocular, que substitui o uso manual do mouse. O Tobii é capaz de captar o movimento dos olhos, o que o permite, portanto, ser utilizado como mouse.

\section{- VIA GEGC}


Considerando o uso do Tobii nas interações com o site e a dificuldade de alguns dos alunos fixarem o olhar onde se quer clicar, a interface foi desenhada cuidadosamente para que não haja grandes dificuldades de clique. A área dos botões é grande o bastante para facilitar a seleção e, além disso, as opções e informações presentes na tela são apenas as necessárias para a interação do aluno com a plataforma, minimizando distrações. Muitas informações na interface apenas dificultam a navegação de um usuário de eye-tracking, fazendo com que percam o foco e errem o clique.

O site foi setorizado em exercícios, jogos e histórias. Cada um possui suas subdivisões, como o tipo de exercícios, seleção de jogos e histórias.

A plataforma foi desenvolvida com a linguagem de marcação $H T M L$ e, para melhorar a apresentação da estrutura, foi usada a linguagem de folhas de estilo CSS. Junto a essas linguagens, para dar dinamicidade a algumas interações, como o clique de botões, a linguagem JavaScript foi aplicada.

Diferentes ferramentas foram utilizadas no desenvolvimento do website, o Photoshop, por exemplo, foi usado para criar a interface gráfica do site, tais como botões e visual dos exercícios implementados. O código foi escrito através do editor Visual Studio Code, que auxiliou no desenvolvimento da plataforma utilizando o conjunto de linguagens.

\section{Resultados e discussão}

\section{Levantamento das Necessidades dos usuários}

Para se extrair as necessidades dos usuários, e por consequência, os requisitos do website, foram consultados diversos autores das áreas de Ergonomia e Interface HumanoComputador (IHC). Um conjunto de princípios e heurísticas foram selecionados e adaptados ao contexto do website aqui proposto, e a partir disso, foi possível a elaboração da matriz de qualidade.

Para o levantamento das necessidades dos usuários, foram acompanhada sessões de atendimentos especializados (AEE) com dois estudantes no contraturno escolar. O estudante 2 , conseguiu controlar de maneira bastante satisfatória as ferramentas computacionais através do rastreamento ocular com o equipamento Tobii para a utilização do website. O estudante 1 teve maiores dificuldades em manter o foco no ponto de clique, o que levou ao aumento dos botões da interface. Antes de iniciar a sessão, a professora realizava o processo de calibragem com o estudante 1, para ajustar o recurso ao seu olho. Foi notado que, frequentemente, o participante não conseguia bons resultados com a calibragem nos pontos inferiores da tela

\section{- VIA GEGC}




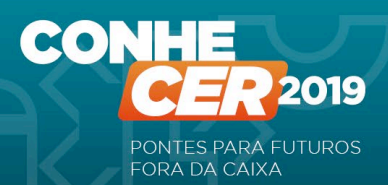

(inferior esquerdo, inferior, inferior direito). Isso foi importante para a elaboração do design do website, uma vez que esses pontos na tela precisaram ser evitados.

Os alunos que utilizam o Tobii usam, frequentemente, o software Communicator, da própria empresa desenvolvedora. Ao usar qualquer outra ferramenta do computador fora do Communicator, o aluno precisa do suporte de um mouse auxiliar que aparece no canto direito da tela. Nele, há botões de "1 clique" e "2 cliques", que precisa selecionar antes de clicar em qualquer ponto da tela. Isso impediu o desenvolvimento de um teclado virtual no site, já que o aluno teria trabalho para selecionar uma letra, pois precisaria clicar em dois botões, ao invés de um só.

Após realizadas as sessões de acompanhamento e entrevistas no colégio e baseando-se nos princípios e critérios acima mencionados, foi possível extrair uma lista de necessidades, ou qualidades demandadas, no caso, professoras e alunos. Essas qualidades dizem respeito tanto à interface gráfica do site quanto a funcionalidade, segurança, performance, estrutura de manutenção, personalização, segurança e atualização.

A Matriz de Qualidade teve como resultado uma lista de requisitos necessários para o website proposto. Através da pontuação obtida, os requisitos puderam ser ordenados por grau de importância, como pode ser visto na tabela 1 .

\begin{tabular}{|c|c|c|}
\hline \multicolumn{2}{|c|}{ Requisitos técnicos do we bsite } \\
\hline$\#$ & Requisito & Pontos \\
\hline 1 & Ícones, botões, figuras e textos grandes & 201 \\
\hline 2 & Alto contraste entre figuras, botões, textos e imagens com o fundo & 159 \\
\hline 3 & Teclado virtual & 150 \\
\hline 4 & Design limpo e colorido & 146 \\
\hline 5 & Permitir construção de diferentes tipos de questionários & 145 \\
\hline 6 & Uso de cores & 132 \\
\hline 7 & Área de "clique" grande & 129 \\
\hline 8 & Salvar registro de atividades & 117 \\
\hline 9 & Guia de uso para o website & 116 \\
\hline 10 & Permitir construção de placas de comunicacão alternativa & 87 \\
\hline 11 & Uso de cadastro de professores, alunos, bolsistas e público & 81 \\
\hline 12 & Feedback imediato das respostas do usuário & 73 \\
\hline 13 & & 60 \\
\hline 14 & Permitir criação de plano de atividades da sessão, pela professora & 56 \\
\hline
\end{tabular}

Tabela 1 - Resultado do QFD: Ranking dos requisitos do website.

Fonte: Autores, 2016

A figura 1 mostra parte da solução final do design do website, que atende a maior parte dos requisitos extraídos da Matriz QFD. É possível ver na imagem abaixo como os ícones, botões e textos tem um tamanho grande em comparação com a área total da página. Além disso, o fundo branco foi utilizado para dar um contraste maior com os botões e textos, que utilizam, em sua maior parte, das cores primárias. O design do site é econômico, mostrando na tela 
apenas o essencial, a fim de não haver confusão visual para o aluno. Foi evitado, o máximo possível, os cantos inferiores da tela, devido a uma dificuldade do participante 2 , em focar nessa área da tela do computador.

Em todas as páginas há um pictograma, onde, ao ser clicado, direciona o aluno para uma página de placas de comunicação alternativa. Em todas as páginas abaixo da Homepage também foi incluído um grande botão de "voltar", permitindo ao aluno sempre retornar para a página anterior. No caso das páginas com exercícios, foi incluído um grande botão de “avançar", para o aluno seguir para a próxima pergunta quando acabar de responder a atual.s-pepd

a)

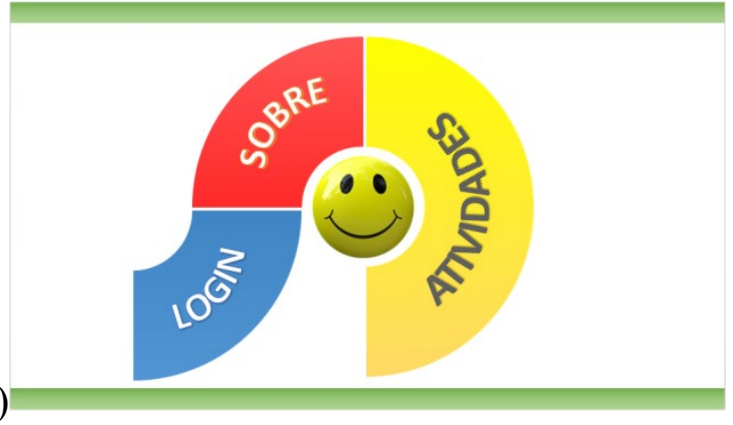

b)

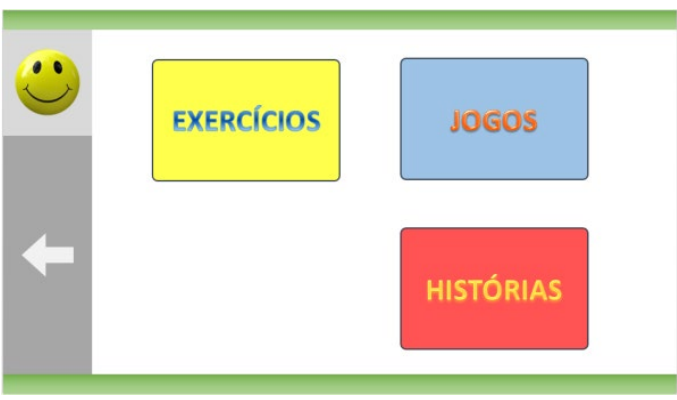

Figura 1 - Tela inicial e tela de seleção de atividades.

Fonte: Autores, 2016

\section{Conclusão}

A inclusão de estudantes com deficiência nas salas de aula é de extrema importância na sociedade atual, e para tanto, cada vez mais se faz necessário que se invista na redução e/ou eliminação das barreiras que dificultam a acessibilidade. Transcorre assim, pelo direito desses ao acesso a produtos, recursos e serviços de TA necessários para a atividade, participação, autonomia e independência no dia-a-dia, reconhecendo aqui um caráter interdisciplinar, o qual permeia diferentes áreas do conhecimento.

Para implementar algum recurso de TA voltado para o aprendizado de estudantes com deficiência num colégio, é preciso analisar o contexto social no qual o/a estudante está inserido/a. Através de observações e entrevistas com os profissionais que atendem estes estudantes, foi possível atender uma demanda de forma inovadora, propondo uma solução que auxiliou o aprendizado desses estudantes e contribuiu para metodologia de ensino das professoras.

O objetivo de estudar este tipo de metodologia de aprendizagem foi planejar e desenvolver um website educacional inclusivo que facilitasse o aprendizado de todos os 
estudantes, mas que contemplasse especialmente os alunos com paralisia cerebral do colégio.

A principal ferramenta utilizada para extrair as características do produto aqui proposto foi a Matriz de Qualidade (QFD - Quality Function Deployment), uma vez que o design do website deveria ser centrado no usuário e em suas necessidades. Através da matriz foi possível estabelecer as inter-relações entre as necessidades dos usuários (estudantes e professoras) e os requisitos técnicos do projeto. Essas necessidades foram definidas com base em critérios e heurísticas de usabilidade, design de interfaces, ergonomia e design de sistemas de navegação. O resultado foi uma lista de características, ordenadas por grau de importância, na qual foi baseada para a criação do design e funcionalidades do produto.

A página web criada é de simples utilização, fácil visualização e aprendizado, e utiliza as cores primárias em seu design. Diversos requisitos foram respeitados, entretanto, alguns deles não puderam ser atendidos. A principal característica proposta para a página que não foi possível desenvolver, devido a limitações técnicas, é o teclado virtual inteligente. Apesar de uma importante necessidade dos estudantes, a configuração do equipamento de rastreamento ocular ofereceria muito mais trabalho aos mesmos, o oposto do que se pretendia.

Finalmente, é importante destacar a importância que esforços para a criação de novas ferramentas assistivas tem, uma vez que auxilia cada vez mais na inclusão de Todos os estudantes no ambiente escolar, proporcionando uma sociedade muito mais igualitária, acessível e inclusiva.

\section{Referências}

ALVES, A., MATSUKURA, T. Percepção de alunos com paralisia cerebral sobre o uso de recursos de tecnologia assistiva na escola regular. Revista Brasileira de Educação Especial, v.17, n. 2, p. 287-304, 2011.

BRASIL. Ministério da Educação. Secretaria de Educação Especial (SEESP). Política Nacional de Educação Especial na Perspectiva da Educação Inclusiva. Brasília: MEC/SEESP, 2008.

BRASIL. Ministério da Educação e Cultura. Resumo técnico - Censo Escolar 2010. Brasília: MEC, Secretaria de Educação Especial, 2011.

BROWNING, N. O desenvolvimento das aptidões literárias da criança com deficiência física. Temas sobre desenvolvimento, São Paulo, v.11, n.64, p.35-41, 2002.

CAT - Comitê de Ajudas Técnicas. Ata da Reunião VII, de dezembro de 2007 do Comitê de Ajudas Técnicas. Secretaria Especial dos Direitos Humanos da Presidência da República (CORDE/SEDH/PR), 2007. 
DUTRA, F. C. M., GOUVINHAS, R. P. Desenvolvimento de protótipo de cadeira de banho para indivíduos com paralisia cerebral tetraparética espástica. Revista Produção, v. 20, n. 3, p. 491-501, 2010.

FICHTEN, C. S., FERRARO, V., ASSUNCION, J. V., CHWOJKA, C., BARILE, M., NGUYEN, M. N., KLOMP, R., WOLFORTH, J. Disabilities and e-learning problems and solutions: an exploratory study. Educational Technology \& Society, v.12, n. 4, p. 241-256, 2009.

GALVÃO FILHO, T. A. e DAMASCENO, L. L. As novas tecnologias e a tecnologia assistiva: utilizando os recursos de acessibilidade na educação especial. Fortaleza, Anais do III Congresso Ibero-americano de Informática na Educação Especial, MEC, 2002.

GALVÃO FILHO, T. A. Tecnologia Assistiva para uma Escola Inclusiva: Apropriação, Demandas e Perspectivas. 2009. 346 f. Tese (Doutorado em Educação) - Faculdade de Educação, Universidade Federal da Bahia, Bahia. 2009.

GARCEZ, J. L. A. F., MACIEL, F. R., CARDOSO, V. M. B. Considerações ergonômicas para aplicação de mídia em ambientes educacionais para crianças do ensino fundamental. Produção. V. 22, n. 2, pp. 284-295, 2012.

GONZAGA, A. Materiais adaptados ajudam a incluir: Recursos flexibilizados favorecem o aprendizado dos estudantes com deficiência e alguns deles podem ser confeccionados na própria escola. Gestão escolar. Junho/julho 2012. Disponível em: http://gestaoescolar.abril.com.br/administracao/materiais-adaptados-ajudam-incluir-

695104.shtml (Acessado em 27/01/2016).

MALLIN, S., DE CARVALHO, H. Assistive Technology and User-Centered Design: emotion as element for innovation. 6th International Conference on Applied Human Factors and Ergonomics (AHFE 2015) and the Affiliated Conferences, AHFE 2015, p.5570-5578, 2015.

PALISANO, R. et al. Development and reliability of a system to classify gross motor in children with cerebral palsy. Development Medical Child Neurologic, v.39, p.214-223, 1997.

ROCHA, A., DELIBERATO, D. Tecnologia assistiva para a criança com paralisia cerebral na escola: identificação das necessidades. Revista Brasileira de Educação Especial, v.18, n. 1, p. 71-92, 2012.

SOARES, M. M.; MARTINS, L. B. Design universal e ergonomia: uma parceria que garante acessibilidade para todos. In: ALMEIDA, A. T.; SOUZA, F. M. C. Produção e competitividade: aplicações e inovações, p. $127-156,2000$.

SONDA, F. A., RIBEIRO, J. L. D., ECHEVESTE, M. E. A aplicação do QFD no desenvolvimento de software: um estudo de caso. Revista Produção, v. 10, n. 1, p. 51-75, 2000 .

SANTAMBROGIO, M.; TZIVISKOU, C.; LE MOLI, G. MorfWeb: A New Way of Living the Web Access. In: International Conference On Information And Communication Technologies And Development, 2006, California. Disponível em: 
$<$ http://ieeexplore.ieee.org/document/4085545/>. Acesso em: 11 Maio 2017. Web Accessibility Initiative (WAI). Disponível em: $<$ http://www.w3.org/WAI/ $>$. Acesso em: 14 Jul. 2016.

Web Content Accessibility Guidelines (WCAG). Disponível em: $<$ http://www.w3.org/TR/WCAG20>. Acesso em:14 Jul. 2016. 